\title{
Morphology and tensile properties of thermoplastic polyurethane-halloysite nanotube nanocomposites
}

\section{Tayser Sumer Gaaz ${ }^{1,2,}$, Abu Bakar Sulong1, Majid Niaz Akhtarªnd Muhammad Rafi Raza ${ }^{1}$}

${ }^{1}$ Department of Mechanical \& Materials Engineering, Faculty of Engineering \& Built Environment, Universiti Kebangsaan Malaysia.

${ }^{2}$ Department of Equipment's \& Machines Engineering, Technical College Al-Musaib, Al-Furat Al-Awsat Technical University, Iraq. *Email: taysersumer@gmail.com

Phone: +601121060892

\begin{abstract}
The high aspect ratio of nanoscale reinforcements enhances the tensile properties of a pure polymer matrix. Researchers have reported the morphology and tensile properties of thermoplastic polyurethane and halloysite nanotube (TPU-HNTs) nanocomposites, formed through compression moulding processes. Few researchers have reported on TPU-HNTs formed through injection moulding. Therefore, the present work investigates the tensile properties of TPU and HNT nanocomposites via injection moulding. TPU and HNTs were mixed using a brabender mixer with concentrations ranging from $1 \mathrm{wt} . \%$ to $15 \mathrm{wt} . \%$ and varying mixing parameters (i.e., mixing speed, mixing time, and mixing temperature). Tensile bars were injection moulded by varying the moulding parameters (i.e., injection temperature, injection time, and injection pressure). A significant increment of tensile strength was found at 1wt.\% HNT reinforcement. TPU-HNT nanocomposite with $1 \mathrm{wt} . \%$ reinforcement exhibited tensile strength of $24.3 \mathrm{MPa}$, which was higher than that of pure TPU. The Young's modulus of the TPU-15wt.\% HNT nanocomposite was $21.5 \mathrm{MPa}$. Thus, TPU-HNT had improved mechanical properties, compared to pure TPU, due to the addition of a nanofiller.
\end{abstract}

Keywords: Nanocomposites; thermoplastic polyurethane; halloysite nanotubes; mechanical properties.

\section{INTRODUCTION}

Thermoplastic Polyurethanes (TPUs) are linear segmented co polymers that are composed of hard and soft segments separated at a micro-phase. The investigation of the microstructure development under an applied load is complicated [1]. Conventional TPUs are among biomaterials not intended to degrade, but are susceptible to hydrolytic, oxidative and enzymatic degradation in vivo [2]. TPUs are extremely versatile materials that can display properties ranging from being very soft thermoplastic elastomers to being strong, rigid thermoplastics, depending on their chemical compositions, backbone structures and resultant microphase morphologies [3]. TPU is one of the most attractive engineering thermoplastics with elastomeric properties [4]. In addition, TPU is a unique polymeric material with special physical-chemical properties [5]. Besides that, TPU is 
used in products in the group of engineering thermoplasticswith elastomeric properties [6]. TPU may also be subjected to different environmental conditions that affect its mechanical properties [7]. In particular, the TPUs, which are generally described as "bridging the gap between rubber and plastics", impart high elasticity combined with high abrasion resistance. That is why TPU is widely used in industry and consumer products [8]. Thermoplastic elastomers (TPEs) exhibit functional properties of conventional vulcanized rubber, yet can be processed on thermoplastic fabrication equipment. Such materials can be produced either as block copolymers or as blends [9]. Polyurethane (PU) foam is a versatile engineering material with a wide range of applications because of its properties, and can be readily tailored by the type and composition of its component [10]. Over recent decades, many polymer composites have been prepared and combined with various types of synthetic reinforcing fillers, in order to improve their mechanical properties and obtain those characteristics demanded by actual applications [11].

Halloysite nanotubes (HNTs), which are mined from natural deposits, are a naturally occurring aluminosilicate $\left[\mathrm{Al}_{2} \mathrm{Si}_{2} \mathrm{O}_{5}(\mathrm{OH})_{4} \cdot 2 \mathrm{H}_{2} \mathrm{O}\right]$ that have a predominantly hollow tubular structure [12]. HNTs have recently gained considerable attention as a new type of nano-additive for enhancing the mechanical [13-15], thermal, crystallization [16, 17], and fire performance of thermoplastic polymers, such as polypropylene and polyamide-6 [18], and thermosets, such as epoxy [19]. In recent years, the assembly of ordered metal nanoparticleson one-dimensional nanotubes to synthesize nanocomposites has attracted a great deal of attention in the field of electroanalytical chemistry; particularly in electrochemical sensors [20]. Polymerhalloysite composites are propective materials used for medical implants, such as for bone repair [21, 22]. Large-scale production causes the nanotubes to be easily entangled, making it difficult to disperse them in polymer matrix. As such, chemical functionalization, in situ polymerization, and enhanced polymer blending have been performed to address this dispersion issue [23]. On the other hand, Agglomeration of particles will take place if the reaction rate is too slow. Moreover, the choice of the surfactant is critical since it determines the stability, solubility, reactivity, dispersibility and even the size and shape of the nanotubes during the synthesis [24]. The unique crystal form of HNTs and the surface is characterized by hydroxyl with a lower level of density that permits smooth diffusion in a polymer matrix compared to other nanoclays. More importantly, the unique crystal structure of HNTs not only resembles that of CNTs in terms of aspect ratio, but also has a highly ordered structure with aluminol groups bound in the inner surface and silanol groups on the external surface [25]. Ning et al. observed little improvement of tensile and impact strength of PP (Polypropylene)/HNT composites of injection molded bars by adding even $10 \mathrm{wt} \%$ of HNTs, and this could be mainly due to the constant crystallinity and unchanged spherulite size of PP as well as the small length/diameter ratio of HNTs [26].

The main goal of this research is to study the effects of the distribution and dispersion of HNT in TPU prepared by extrusion and injection moulding. Extrusion and injection moulding have been applied within the bio-medical industry. In this paper, the intention is to eliminate the use of HNT content and the homogeneity of dispersion. The proportion of HNT is increased in the TPU matrix and it is shown that the tensile properties are enhanced as a result. 


\section{EXPERIMENTAL DETAILS}

\section{Materials}

Thermoplastic polyurethane (TPU) was supplied by Global Innovations-Polycarbonates Bayer Material Science AG, D-51368 Leverkusen. Halloysite nanotubes (HNTs) were supplied by Natural Nano, Inc., 832 Emerson Street Rochester, New York 14613. Table 1 and Table 2 show the chemical compositions and physical properties of HNTs respectively. All the materials used are in their original form, without any further purification.

Table 1. Chemical compositions of HNT.

\begin{tabular}{llllll}
\hline Chemical compositions & $\mathrm{SiO}_{2}$ & $\mathrm{Al}_{2} \mathrm{O}_{3}$ & $\mathrm{Fe}_{2} \mathrm{O}_{3}$ & $\mathrm{MgO}$ & $\mathrm{TiO}_{2}$ \\
\hline Weight $\%$ & 61.19 & 18.11 & 0.49 & 0.10 & 20.11 \\
\hline
\end{tabular}

Table 2. Physical properties of HNT.

\begin{tabular}{ll}
\hline Typical analysis of natural HNT & \\
\hline Chemistry & $\mathrm{Al}_{2} \mathrm{Si}_{2} \mathrm{O}_{5}(\mathrm{OH})_{4} \cdot \mathrm{nH}_{2} \mathrm{O}$ \\
d50(median particle size) & $1.0 \mu$ \\
Aspect ratio (L/D) & $\sim 15$ \\
Surface area (BET) & $65 \mathrm{~m}^{2} / \mathrm{g}$ \\
Specific gravity & $2.54 \mathrm{~g} / \mathrm{cm}^{3}$ \\
Refractive Index & 1.54 \\
\hline
\end{tabular}

\section{Characterization of HNTs}

TEM images of Neat HNT are shown in Figure 1(a). The Neat HNT present predominate HNT, among which exhibit some alumite plates [27]. The lengths of HNT are $0.5-5 \mu \mathrm{m}$, and their inner diameter and outer diameter are 10-30 nm and 50-100 $\mathrm{nm}$, respectively. Figure1(b) shows a dimension single HNT, showing inner diameter of about $16.02 \mathrm{~nm}$ and outer diameter of about $55.89 \mathrm{~nm}$.
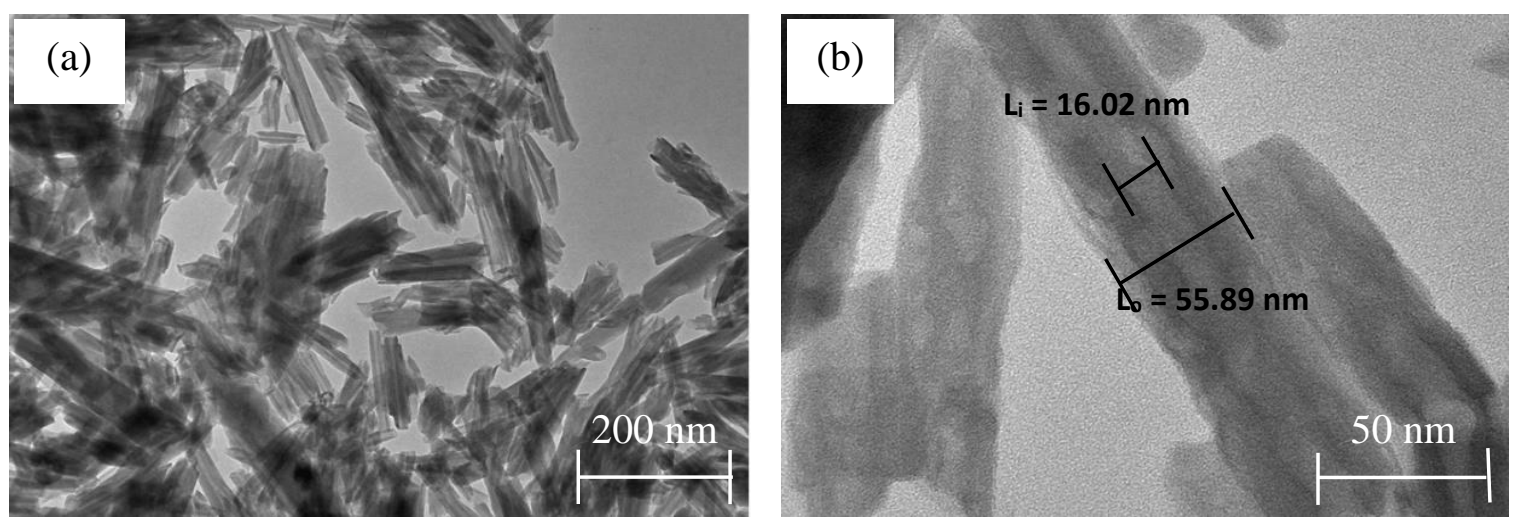

Figure 1. TEM images of Neat HNT: (a) multiple HNT 13000x, (b) a dimension single HNT 100000x. 
Figure 2 presents the TGA curve of Neat HNT. TGA curve shows two main stages of weight loss. The first stage that occurs at $30 \circ \mathrm{C}$ and ends at $100 \circ \mathrm{C}$ may be attributed to the dehydration of physisorbed water and interlayer water. The weight loss of Neat HNT at this stage is higher, where the weight loss may be attributed to the dehydration and destruction of HNT.

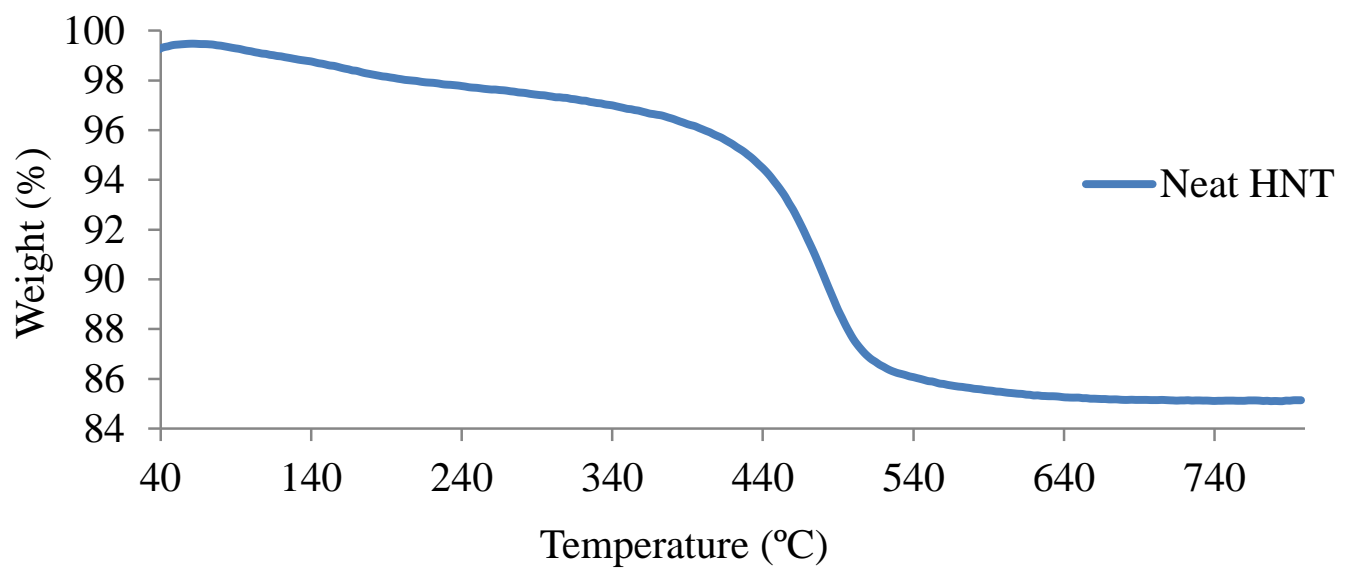

Figure 2. TGA curve of Neat HNT.

\section{Preparation of TPU-HNTs Nanocomposites}

TPU and HNT were dried in a vacuum oven at a temperature of $70{ }^{\circ} \mathrm{C}$ for $14 \mathrm{~h}$. TPU and HNT were homogenized using Brabender Machine. The following Figure 3 (a, b, and c), shows the fabricated TPU nanocomposite samples at different HNT loading percentages, namely $(0,1,15 \mathrm{wt} . \% \mathrm{HNT})$. This experiment was performed until the injection moulding specimen was obtained as shown in the following Figure 4.

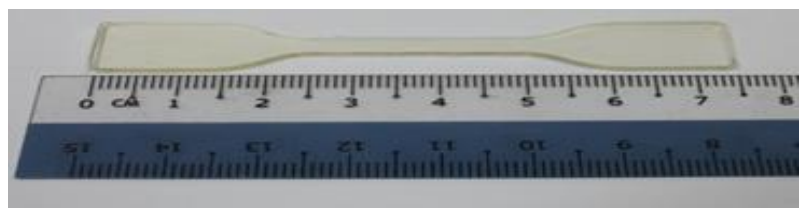

(a) Neat TPU

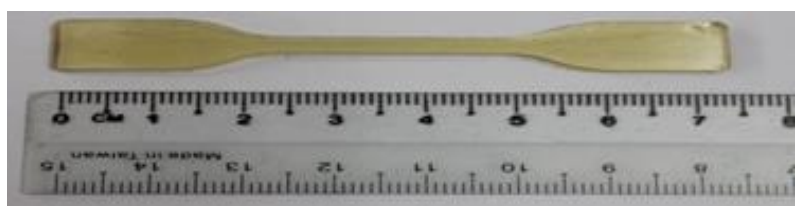

(b) TPU-1\%.wt HNT

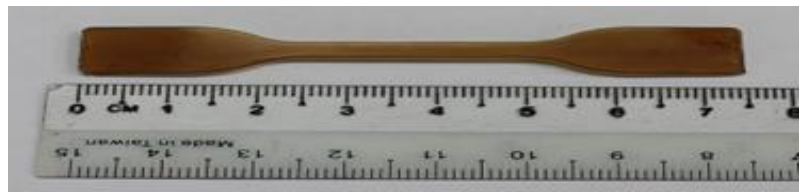

(c) TPU-15\%.wt HNT

Figure 3. Samples of TPU-HNT nanocomposites. 


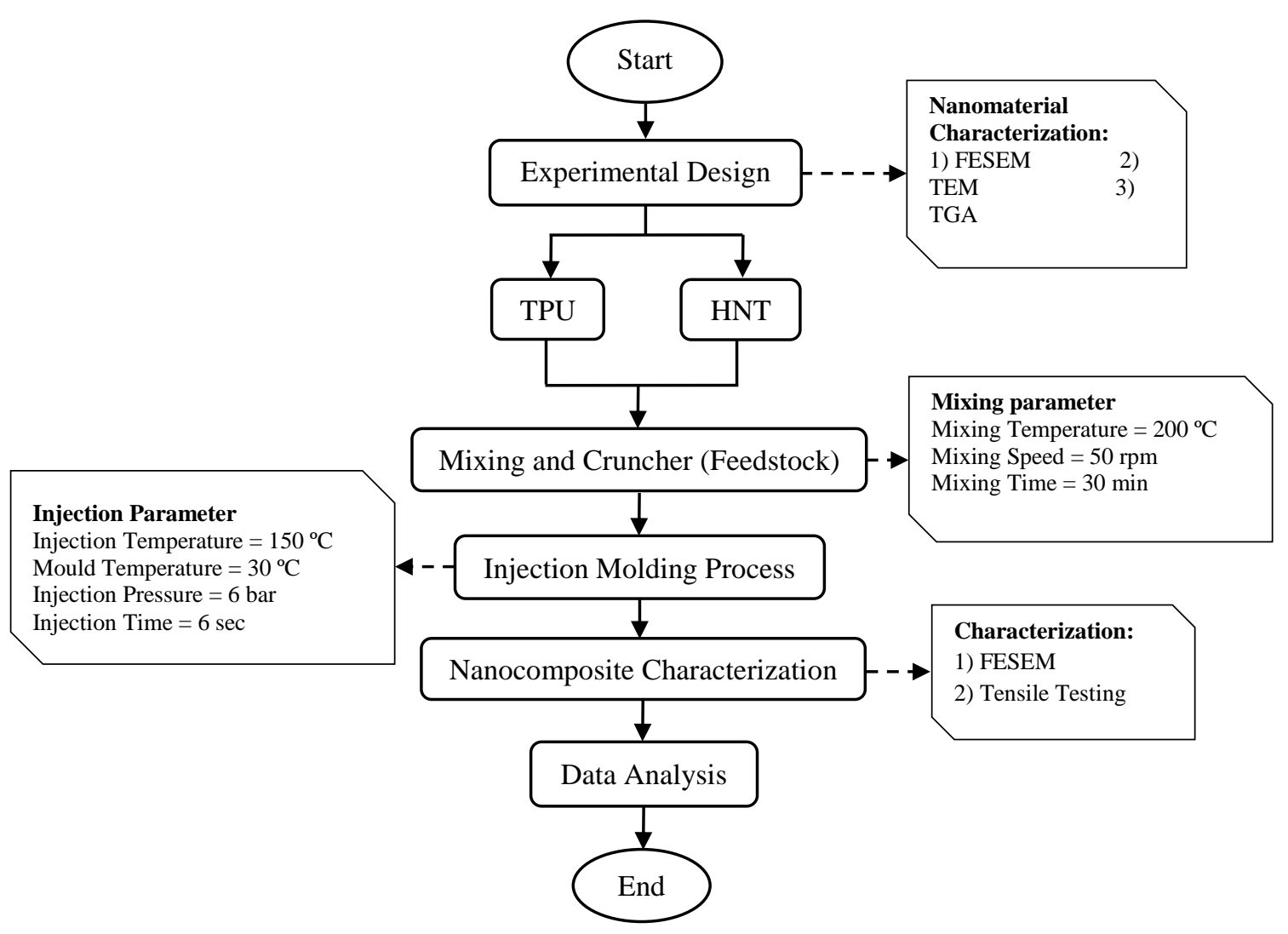

Figure 4. Experimental steps.

\section{Testing Equipment}

Morphologies of the blend samples were investigated using Field Emission Scanning Electron Microscopy (FESEM) ZEISS SUPRA 55-VP. Equipped OXFORD EDS and Mapping. Tensile tests were determined using an Instron universal testing machine (INSTRON 5567), with a 200 Newton load transducer, according to the ASTM D-638 type $\mathrm{V}$ method standard. The crosshead speed was $50 \mathrm{~mm} / \mathrm{min}$ and all tests were performed at room temperature. Five measurements were carried out for each data point.

\section{RESULTS AND DISCUSSION}

\section{Morphology Characterization}

Figure 5 shows the FESEM microphotograph morphologies of the TPU-HNT nanocomposites, to observe the dispersion and distribution of the nanotubes and their physical interactions with the TPU matrix. The HNT dispersion in the TPU matrix, clearly observed from the FESEM images with low magnification, shows that the nanotubes are homogeneously dispersed throughout the TPU matrix as shown in Figure 5 (b). No indication of porosity and voids were observed due to the appearance of strong interfacial bonding between the nanotubes and the TPU matrix [28]. It is also observed from the micrographs that plastic deformation is prominent in the nanocomposites with higher HNT content, because of the strong reinforcing effects of the HNT nanophase and a large percentage of the amorphous region in the TPU matrix [28]. 

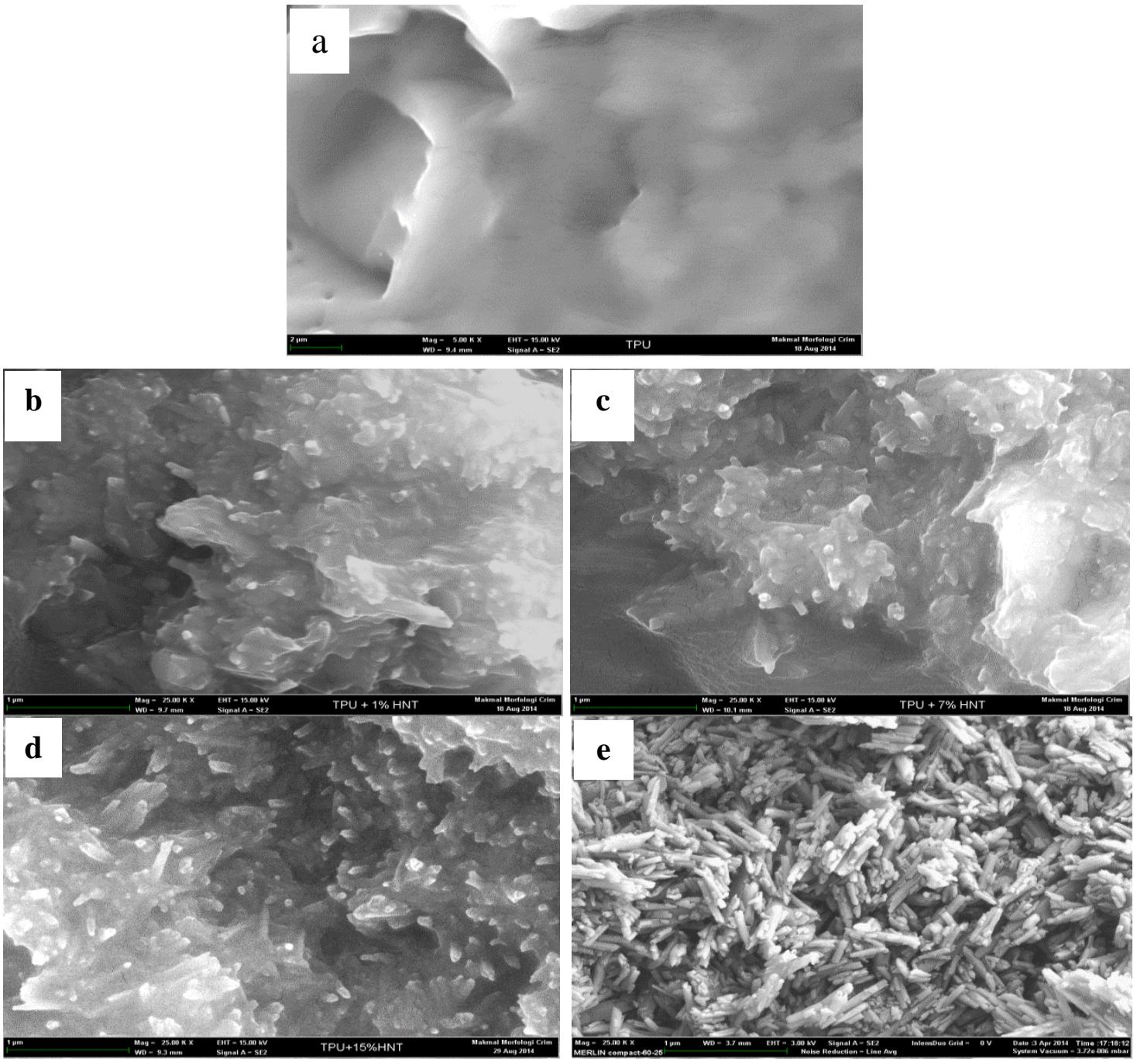

Figure 5. FESEM image of (a) Neat TPU, (b) 1wt.\% HNT, (c) 7wt.\% HNT, (d) $15 \mathrm{wt} . \%$ HNT and (e) Neat HNT.

The Polyurethane (PU) used in this study is a type of thermoplastic. The HNT particles are distributed and dispersed in the TPU matrix. Hence, the small particles that are protruding on the surface of TPU matrix could be assigned to HNTs. It is believed that the small particles present on the TPU-HNT sample correspond to the HNT particles. EDX analysis results are shown in Figure 6 (a) - (e). Figure 6 (a) Neat TPU, (b) TPU-1wt.\% HNT, (c) TPU-7wt.\% HNT, (d) TPU-15wt.\% HNT, and (e) Neat HNT show, because it was observed that there were four elements, namely $\mathrm{C}, \mathrm{O}, \mathrm{Al}$ and $\mathrm{Si}$. The carbon and oxygen are caused by the polymer chain used as the backbone of the composites. In this study, $\mathrm{C}$ and $\mathrm{O}$ contribute to the major proportions that represent the TPU matrix, while the $\mathrm{O}, \mathrm{Al}$, and Sielements represent the components of HNT. Barrientos-Ramirez et al. [29] suggested that the addition of nano-sized particle additives will improve intercalation. They observed through FESEM micrographs that HNT particles were separated into much smaller stacks and dispersed homogenously throughout the TPU matrix when HNT particles were added. Therefore, the wettability and intercalation capability of nanocomposites increases by adding a small proportion of HNT particles. 

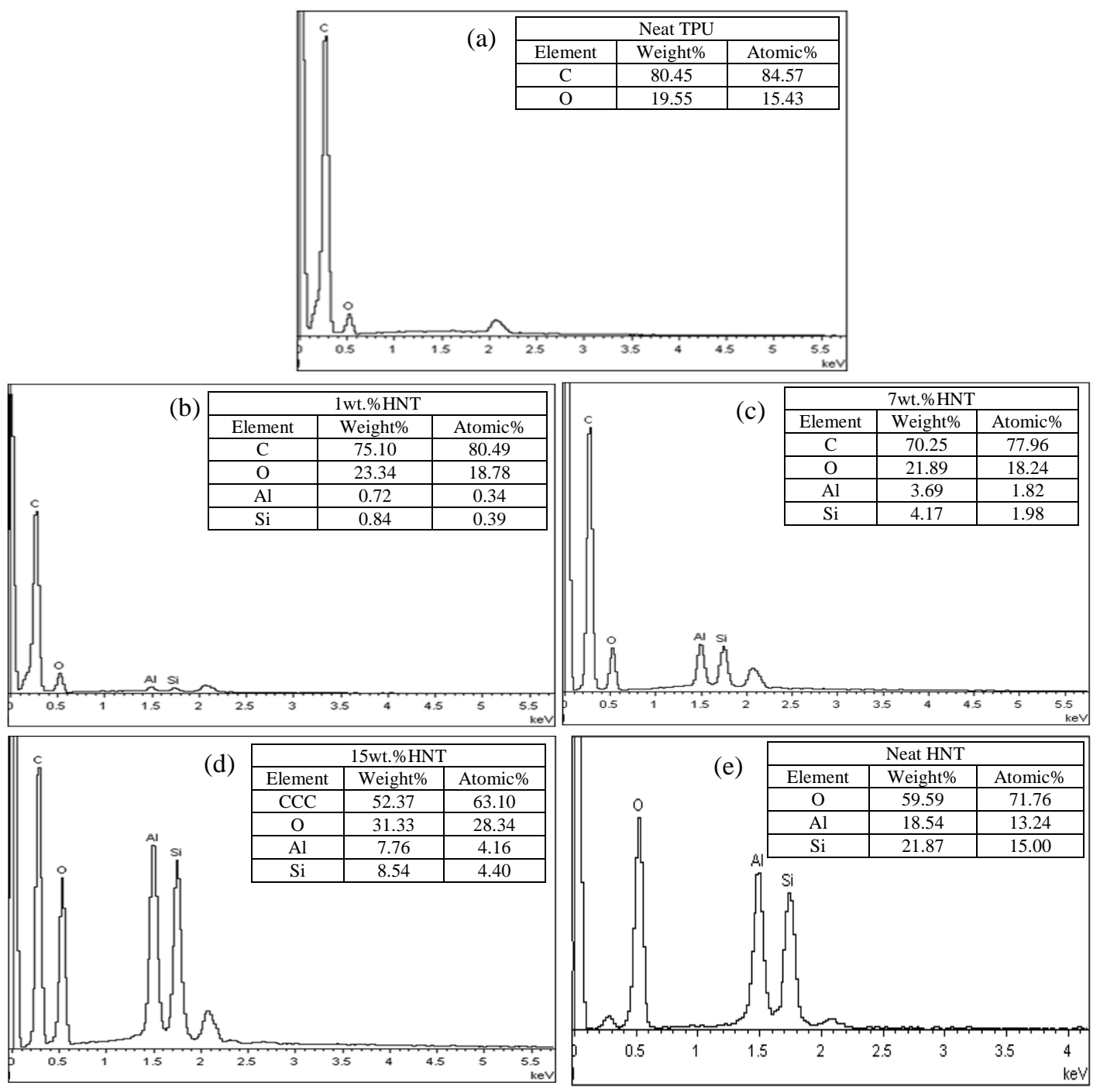

Figure 6.EDX spectra of (a) Neat TPU, (b) 1wt.\% HNT, (c) 7wt.\% HNT, (d) 15wt.\% HNT and (e) Neat HNT.

\section{Tensile Properties}

Figure 7 shows that the tensile stress values were $24.3 \mathrm{MPa}, 6.2 \mathrm{Mpa}$, and 4.8 $\mathrm{MPa}$; which correspond to $1 \mathrm{wt} . \%$, $7 \mathrm{wt} . \%$, and $15 \mathrm{wt} . \%$ HNT loadings, respectively, added to the TPU. Conclusively, of all compositions, TPU-1wt.\% HNT yielded the highest tensile stress value (i.e., 24.3 MPa) while the lowest value measured (i.e., $4.8 \mathrm{MPa}$ ) was TPU-15wt.\% HNT. At TPU-1wt.\% HNT loading, the nanocomposites had better interaction between the matrix and the HNT reinforcement surface. Because of the good dispersion of HNT in TPU and good interaction between the layered silicate of HNT and the TPU chains as mentioned before [30]. This leads to improved bond stress, which results in the highest tensile stress. At higher loading (e.g., above TPU-7wt.\% HNT), the tensile stress decrease may be attributed to the agglomeration of the HNT nanotubes, which resulted in poor interaction between the matrix and the HNT surface [31]. 


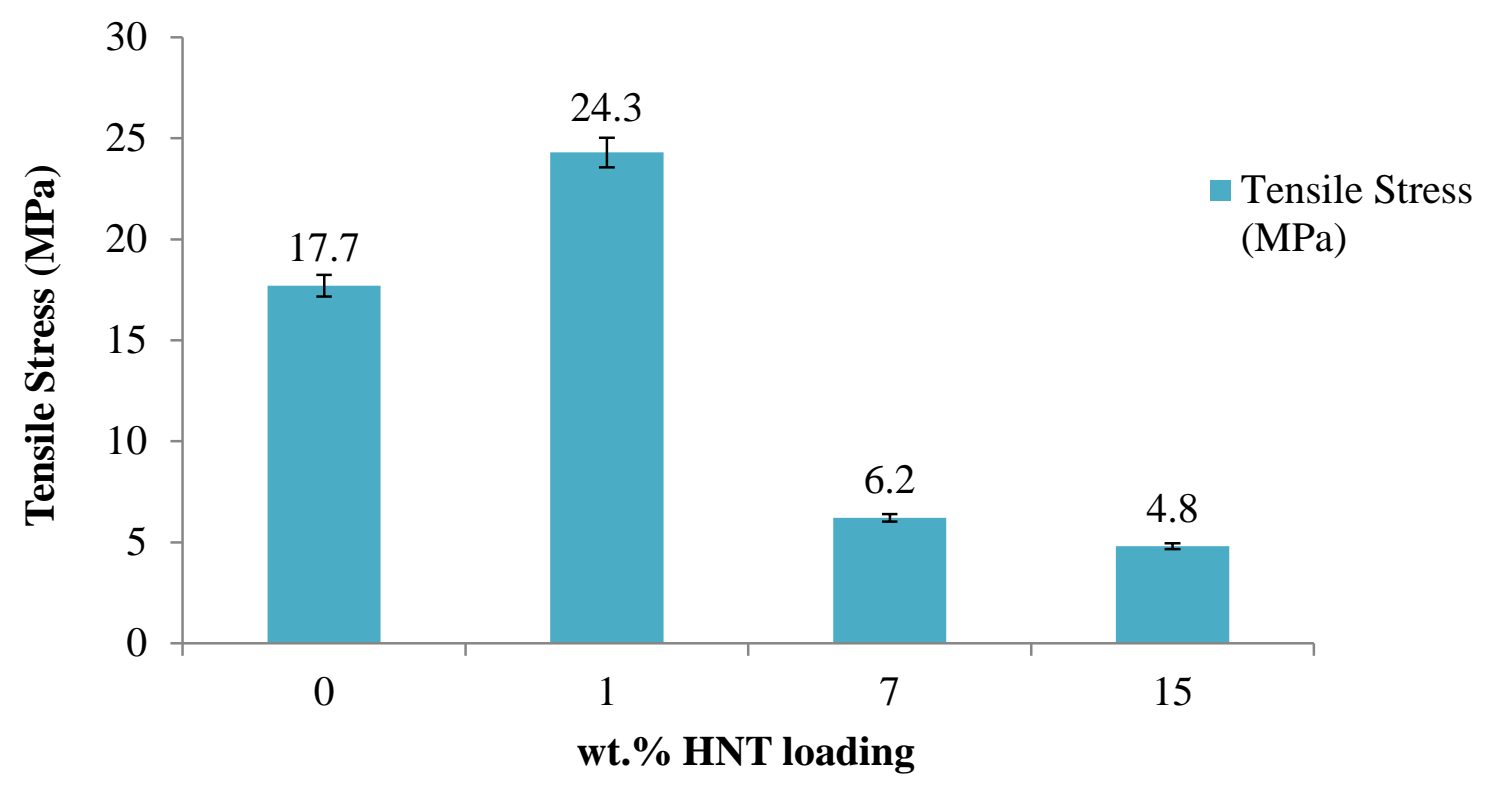

Figure 7. Tensile stress of the TPU-HNT nanocomposites.

From Figure 8, it can be observed that the Neat TPU showed the highest elongation at break value of $353.74 \mathrm{~mm}$ (from 0wt.\% HNT loading). It can also be observed from Figure 8 that elongation at break values decrease with increased loading of HNT. For TPU-1wt.\% HNT the value is $320.02 \mathrm{~mm}$, which means that the value of stiffness showed the smallest stiffness among the others, which decreased the elongation at break when the wt.\% HNT loading increased at other values of TPU-HNT. This decreasing trend continues with the increase of nanofiller loading, where the value reaches $91.7 \mathrm{~mm}$ at $15 \mathrm{wt}$.\% HNT loading. The monotonic decrease of elongation at break with the increase of HNT loading means the value of stiffness increases with the increase of HNT loding. Neat TPU showed the lowest stiffness value of all that decreased the elongation at break, when the wt.\% HNT loading increased at other values of TPU-HNT. Finally, the highest stiffness value of all samples recorded was at an elongation at break value of $91.7 \mathrm{~mm}$ for the TPU-15wt.\% HNT sample.

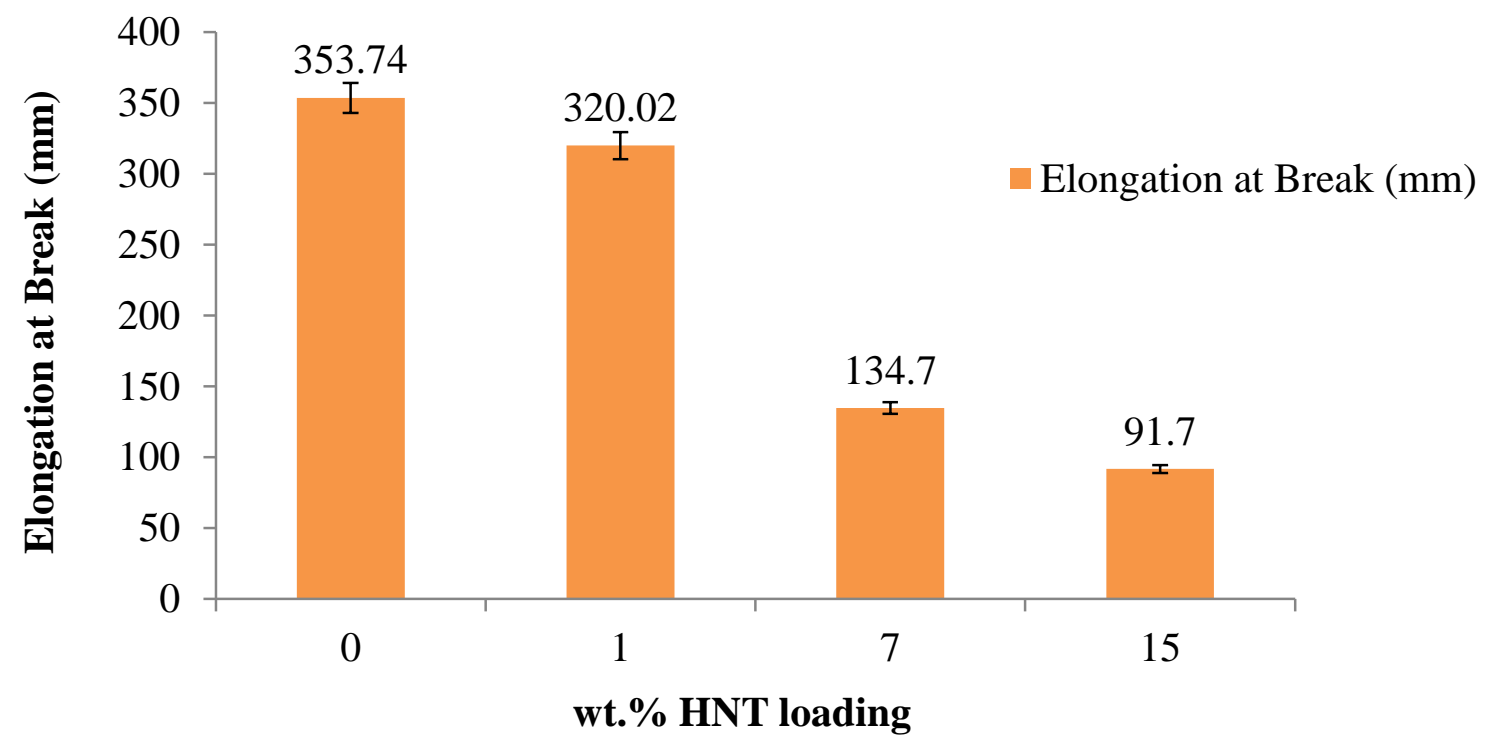

Figure 8. Elongation at break of the TPU-HNT nanocomposites 
From Figure 9, the maximum load value of $408.4 \mathrm{~N}$ was observed for TPU1wt.\% HNT. Meanwhile, 7wt.\% HNT loading shows the lowest maximum load value result of $100.9 \mathrm{~N}$. The maximum load value decreased with the increase of HNT loading to $70.7 \mathrm{~N}$, which corresponds to $15 \mathrm{wt} . \% \mathrm{HNT}$. TPU-1wt.\% HNT gave the highest value of $408.4 \mathrm{~N}$, and TPU-15wt.\% HNT gave the lowest value of $70.7 \mathrm{~N}$ due to the smallest stiffness among the others.

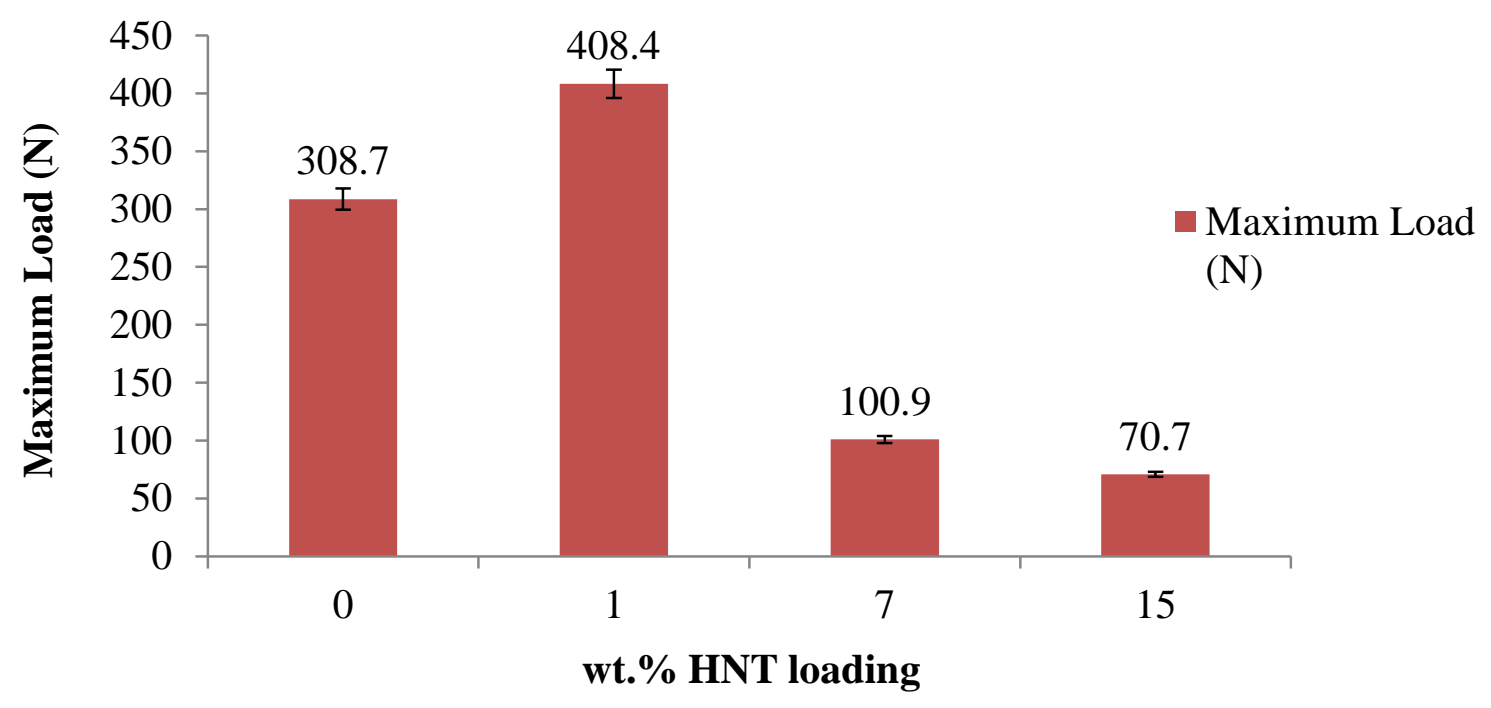

Figure 9. Maximum load of the TPU-HNT nanocomposites.

Figure 10 shows that the TPU-15wt.\% HNT composite had the highest Young's modulus value (i.e., 21.5 MPa), thus showing an increased Young's modulus (from $0 \mathrm{wt} . \%$ to $15 \mathrm{wt} . \%$ of HNT loading). TPU-HNT had the highest stiffness value at $15 \mathrm{wt} . \%$ HNT loading. This increase in modulus may have been due to the stiffness factor, where the nanosized HNT fillers were bonded to the TPU; thus, the mobility of the molecule was arrested. For this reason, the flexibility was reduced, and the stiffness was increased.

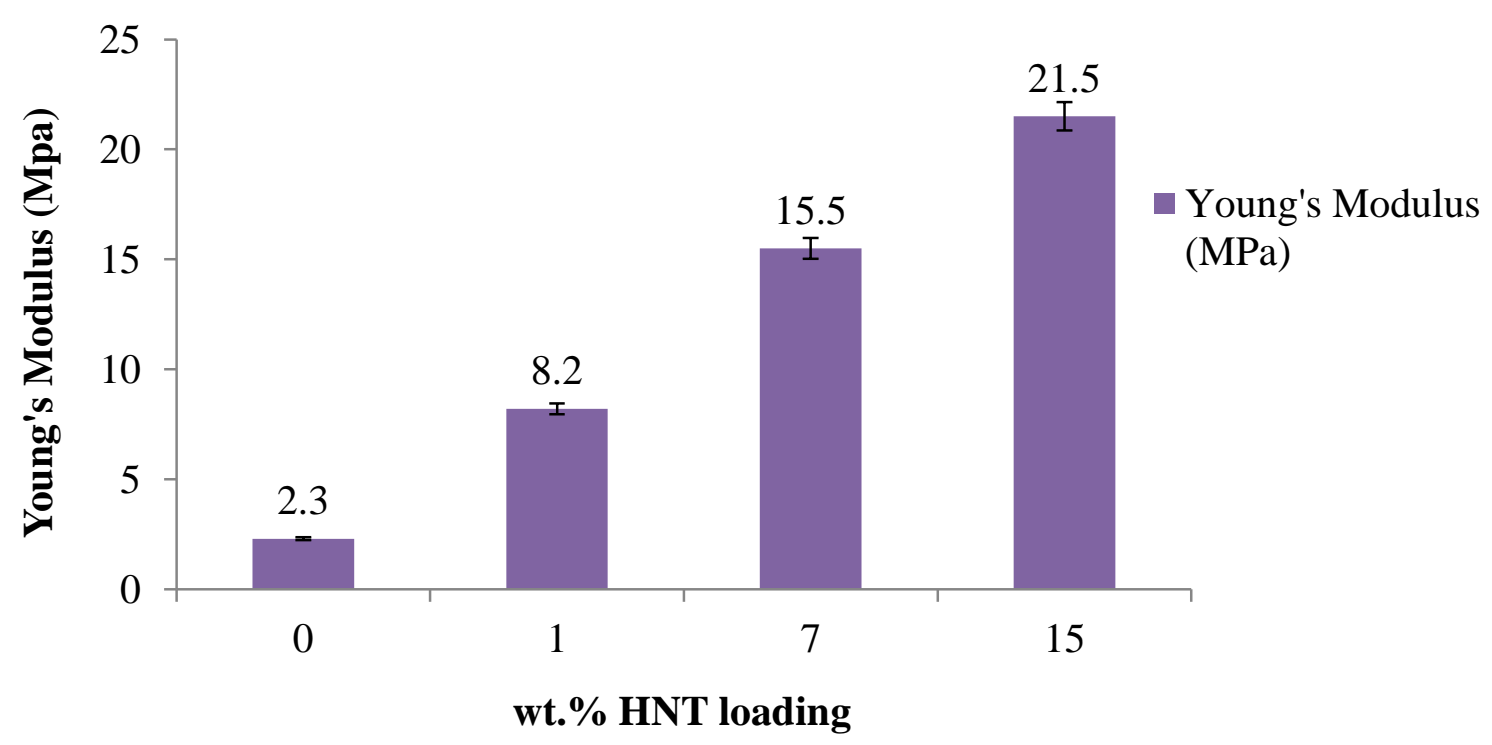

Figure 10. Young's modulus of the TPU-HNT nanocomposites. 


\section{CONCLUSIONS}

TPU-HNT nanocomposites of high modulus and strength were prepared. The nanocomposites exhibited improved properties when combined with nanoparticles in the matrix. These nanocomposites, with filler loading, provide traditional composite properties with all of the advantages of nanocomposites. The HNT have a high aspect ratio that is crosslinked with TPU that facilitates stress transfer from the matrix. Therefore, the matrix is less ductile than a thermoplastic via the physical cross links, but with the continued ability to be thermoformed into various shapes. TPU-HNT nanocomposites, with the enhanced properties of TPU, were achieved with HNT loadings, ranging from $1 \mathrm{wt} . \%$ to $15 \mathrm{wt} . \%$. Further work should be embarked upon in order to recognize the various properties of TPU-HNTs nanocomposites. In order to achieve these targets, some recommendations are outlined such as a study on other mechanical properties such as fatigue life, in order to evaluate the viability of the nanocomposite. Other thermal analysis techniques, such as Differential scanning calorimeter (DSC) to enhance the data accuracy and reliability when studying the thermal properties of nanocomposites, are recommended.

\section{ACKNOWLEDGEMENTS}

The authors thank Universiti Kebangsaan Malaysia and the Ministry of Higher Education for the grants and financial support TRGS/2/2014/UKM/02/4/1 and LRGS/TD/2012/USM-UKM/PT/05.

\section{REFERENCES}

[1] Li C, Han J, Huang Q, Xu H, Tao J, Li X. Microstructure development of thermoplastic polyurethanes under compression: The influence from first-order structure to aggregation structure and a structural optimization. Polymer. 2012;53:1138-47.

[2] Tatai L, Moore TG, Adhikari R, Malherbe F, Jayasekara R, Griffiths I, et al. Thermoplastic biodegradable polyurethanes: The effect of chain extender structure on properties and in-vitro degradation. Biomaterials. 2007;28:5407-17.

[3] Yilgor I, Yilgor E, Guler IG, Ward TC, Wilkes GL. FTIR investigation of the influence of diisocyanate symmetry on the morphology development in model segmented polyurethanes. Polymer. 2006;47:4105-14.

[4] Wang X, Luo X. A polymer network based on thermoplastic polyurethane and ethylene-propylene-diene elastomer via melt blending: morphology, mechanical properties, and rheology. European Polymer journal. 2004;40:2391-9.

[5] Bian J, Lin HL, He FX, Wei XW, Chang I-T, Sancaktar E. Fabrication of microwave exfoliated graphite oxide reinforced thermoplastic polyurethane nanocomposites: Effects of filler on morphology, mechanical, thermal and conductive properties. Composites Part A: Applied Science and Manufacturing. 2013;47:72-82.

[6] Ha CS, Kim Y, Lee WK, Cho WJ, Kim Y. Fracture toughness and properties of plasticized PVC and thermoplastic polyurethane blends. Polymer. 1998;39:4765-72. 
[7] Boubakri A, Haddar N, Elleuch K, Bienvenu Y. Impact of aging conditions on mechanical properties of thermoplastic polyurethane. Materials \& Design. 2010;31:4194-201.

[8] Boubakri A, Elleuch K, Guermazi N, Ayedi H. Investigations on hygrothermal aging of thermoplastic polyurethane material. Materials \& Design. 2009;30:3958-65.

[9] Mohamad N, Zainol NS, Yaakob MY, Abd Razak J. Morphological and mechanical properties of Polyurethane/Epoxidized natural rubber thermoplastic vulcanizates treated with maleic anhydride-grafted polypropylene. International Journal of Automotive and Mechanical Engineering. 2013;8:1305-15.

[10] Hassan M, Normunira N, Rus AZM. Acoustic performance of green polymer foam from renewable resources after uv exposure. International Journal of Automotive and Mechanical Engineering. 2014;9:1639-48.

[11] Hardinnawirda $K$. The effect of rice husks as filler in polymer matrix composites. Journal of Mechanical Engineering and Sciences, 2012; 2:181-6.

[12] Joussein E, Petit S, Churchman J, Theng B, Righi D, Delvaux B. Halloysite clay minerals - a review. Clay Minerals. 2005;40:383-426.

[13] Prashantha K, Lacrampe M, Krawczak P. Processing and characterization of halloysite nanotubes filled polypropylene nanocomposites based on a masterbatch route: effect of halloysites treatment on structural and mechanical properties. Express Polymer Letters. 2011;5:295-307.

[14] Du M, Guo B, Jia D. Newly emerging applications of halloysite nanotubes: a review. Polymer International. 2010;59:574-82.

[15] Liu C, Luo Y, Jia Z, Zhong B, Li S, Guo B, et al. Enhancement of mechanical properties of poly (vinyl chloride) with polymethyl methacrylate-grafted halloysite nanotube. Express Polymer Letters. 2011;5:591-603.

[16] Guo B, Zou Q, Lei Y, Du M, Liu M, Jia D. Crystallization behavior of polyamide 6/halloysite nanotubes nanocomposites. Thermochimica Acta. 2009;484:48-56.

[17] Lecouvet B, Gutierrez J, Sclavons M, Bailly C. Structure-property relationships in polyamide 12/halloysite nanotube nanocomposites. Polymer Degradation and Stability. 2011;96:226-35.

[18] Prashantha K, Schmitt H, Lacrampe M, Krawczak P. Mechanical behaviour and essential work of fracture of halloysite nanotubes filled polyamide 6 nanocomposites. Composites Science and Technology. 2011;71:1859-66.

[19] Deng S, Zhang J, Ye L. Halloysite-epoxy nanocomposites with improved particle dispersion through ball mill homogenisation and chemical treatments. Composites Science and Technology. 2009;69:2497-505.

[20] Cheng W, Dong S, Wang E. Colloid chemical approach to nanoelectrode ensembles with highly controllable active area fraction. Analytical chemistry. 2002;74:3599-604.

[21] Zhou WY, Guo B, Liu M, Liao R, Rabie ABM, Jia D. Poly (vinyl alcohol)/halloysite nanotubes bionanocomposite films: properties and in vitro osteoblasts and fibroblasts response. Journal of Biomedical Materials Research Part A. 2010;93:1574-87.

[22] Yuan P, Southon PD, Liu Z, Green ME, Hook JM, Antill SJ, et al. Functionalization of halloysite clay nanotubes by grafting with $\gamma$ aminopropyltriethoxysilane. The Journal of Physical Chemistry C. 2008;112:15742-51. 
[23] Othman R, Wilkinson A. The impedance characterization of hybrid CNT-Selica Epoxy nanocomposites. International Journal of Automotive \& Mechanical Engineering. 2014;10.

[24] Suriati G, Mariatti M, Azizan A. Synthesis of silver nanoparticles by chemical reduction method: effect of reducing agent and surfactant concentration. International Journal of Automotive and Mechanical Engineering (IJAME). 2014;105:1920-7.

[25] Marney D, Russell L, Wu D, Nguyen T, Cramm D, Rigopoulos N, et al. The suitability of halloysite nanotubes as a fire retardant for nylon 6. Polymer degradation and stability. 2008;93:1971-8.

[26] Ning NY, Yin QJ, Luo F, Zhang Q, Du R, Fu Q. Crystallization behavior and mechanical properties of polypropylene/halloysite composites. Polymer. 2007;48:7374-84.

[27] Zhang AB, Pan L, Zhang HY, Liu ST, Ye Y, Xia MS, et al. Effects of acid treatment on the physico-chemical and pore characteristics of halloysite. Colloids and Surfaces A: Physicochemical and Engineering Aspects. 2012;396:182-8.

[28] Barick AK, Tripathy DK. Preparation, characterization and properties of acid functionalized multi-walled carbon nanotube reinforced thermoplastic polyurethane nanocomposites. Materials Science and Engineering: B. 2011;176:1435-47.

[29] Barrientos-Ramirez S, Oca-Ramírez G, Ramos-Fernandez E, SepùlvedaEscribano A, Pastor-Blas M, Gonzàlez-Montiel A. Surface modification of natural halloysite clay nanotubes with aminosilanes. Application as catalyst supports in the atom transfer radical polymerization of methyl methacrylate. Applied Catalysis A: General. 2011;406:22-33.

[30] Gholami M, Mir Mohamad Sadeghi G. Investigating the effects of chemical modification of clay nanoparticles on thermal degradation and mechanical properties of TPU/nanoclay composites. Journal of Particle Science \& Technology. 2015;1:1-11.

[31] Lecouvet B, Sclavons M, Bourbigot S, Devaux J, Bailly C. Water-assisted extrusion as a novel processing route to prepare polypropylene/halloysite nanotube nanocomposites: structure and properties. Polymer. 2011;52:4284-95. 